\title{
Sustainable Use of Resources - Recycling of RMC Used Wash Water in Mortar
}

\author{
Mr. Ketan Dhodi ${ }^{1}$, Mr. Priyesh Dhodi ${ }^{2}$, Mr. Kanhaiya Varma ${ }^{3}$, Mrs. Mitali Shelke ${ }^{4}$ \\ ${ }^{12345}$ (UG Students, Department of Civil Engineering, St John College of Engineering \& Management, Palghar) \\ ${ }^{6}$ (Associate Professor, Department of Civil Engineering, St John College of Engineering \& Management, Palghar)
}

\begin{abstract}
As the world is progressing in construction of high rise strength structures for which high strength concrete is the predominant requirement in the area of construction. Concrete is the second mostly used construction material after water. A huge quantity of concrete is asked by the society per year. This need of concrete is fulfilled by local RMC plants. But these Ready Mix Concrete factories use lot of fresh water for making of concrete. Here we decided to differentiate alkaline water and total solids from RMC waste sludge. Then we treated alkaline water by various methods such as oil removal and addition of $\mathrm{Hcl}$. After treatment of alkaline water we used both the treated and untreated water in fresh concrete. Total solids will be kept aside for disposal like filling or dumping, thus making it an environment friendly process.
\end{abstract}

.Keywords- RMC, Alkaline Water, Treatment, Oil Removal, Hcl, Total Solids, Environment Friendly.

\section{I- INTRODUCTION}

$\mathbf{T}_{1}$ he RMC industry in India is one of the most growing industry due to various advantages such as superior concrete quality, ease of handling, no need for storage space at site and many more. Water consumption by RMC is more for concreting as well as washing of mixers. RMC plants consume 2000 to 2500 liters of water for washing mixers. At the same time sludge and waste wash water which is considered as hazardous waste which can lead to environmental problems. According to our test observation the typical $\mathrm{Ph}$ value of wash water is almost 12 . Moreover this wash water also considered as problematic due to its high alkaline nature. With addition to this waste wash water also contains high sulphate and chloride content due to cement as a main constituent. The contaminated water were analyzed and compared with WHO (World Health Organization) drinking water standards and CPCB effluent water quality standards. Recent studies demonstrated promising results regarding the reuse of RMC waste water in several ratios with fresh water for concrete production. To determine the compressive strength and flexural strength of concrete at various ages such as 7 days, 14 days and 28 day.

\section{II - OBJECTIVES}

The objective of the project is to treat the waste water from RMC plants collected after the washing of the tanks and containers after the Ready Mix Concrete production, and use the treated water for construction purpose such as curing and making of mortar.

Thus prime objective of the project is to ; 


\section{International Journal of Innovations in Engineering and Science, www.ijies.net}

1. To overcome the scarcity of water.

2. To control the pollution caused to surface water bodies by slurry wash water from RMC plants.

3. To enhance properties of concrete by using slurry water from RMC plants.

\section{III -MATERIALS AND TESTS}

- Type of cement : Portland Pozzolana Cement (PPC) of grade 43

- Fine aggregate : passing through $4.75 \mathrm{~mm}$ is sieve

- Coarse aggregate : passing through $20 \mathrm{~mm}$ is sieve and retaining on $4.75 \mathrm{~mm}$ is sieve

- Water : RMC slurry water, raw water, treated water.

\section{IV-MIX DESIGN}

Mix proportion for M20 grade

Cement: Course aggregate: Fine aggregate $=1: 1.36$ : 2.28

Water cement ratio $=0.4$

\section{V- METHODOLOGY}

RMC waste wash water was collected from nearby RMC plant available. To make waste water useable in concrete production we studied properties and characteristics of collected water sample and carried various process which are explained below.

\subsection{Settling}

In RMC waste water treatment, settling is an operation that removes suspended particles from the waste water to be treated. It is a physical process that consists to separate particles of higher density than water from the liquid in which they are found. These particles are recovered at the bottom of the tank. Thus settling process was used to remove suspended solids from RMC waste water by letting the water stand still for some while.

\subsection{Removal of Oil and Grease}

After settling of water only sludge is separated from RMC waste water. This water still contains oil and grease which is used in RMC plant. It is also known that concrete containing more than $5 \%$ of crude oil contamination reduces compressive strength of concrete by $50 \%$. It is important to separate them as quickly as possible from the RMC waste water to be treated.

We can use gravity separation method. It is the easiest and suitable method to separate oil and grease present in RMC waste water. Gravity separation is the natural process, in which waste water or emulsions are kept in still position so that oil particles are separated from water droplets. Then oil which is having lower specific gravity will form a separate layer above the water which has higher specific gravity.

\subsection{Addition of $\mathrm{HCl}$}

A neutral $\mathrm{pH}$ is 7, which is that you find in natural fresh water. Anything above 7 is alkaline, and anything below is acidic. Portland cement, concretes binding agent, has a $\mathrm{pH}$ of 11 , making it alkaline. For cement to effectively hold the various components within it, it should have a $\mathrm{pH}$ of around 11. The problem is that Portland cement does not resist many acidic compounds well. As the $\mathrm{pH}$ of acids decrease below 6.5, concrete deterioration increases. Solutions with a $\mathrm{pH}$ of 3 or lower are the most harmful. The more concrete deteriorates, the more porous it becomes.

According to various studies $\mathrm{pH}$ of water used for construction purpose should be between 6 to 7.5. Where as ph of the waste water collected is around 11 to 12 . Thus $\mathrm{HCl}$ is used to achieve the desirable $\mathrm{pH}$ value of the RMC waste water.

\subsection{Casting}

We prepared 3 batches of different proportion of water sample.

1) Raw water

2) RMC slurry water

3) $70 \%$ Treated water and $30 \%$ Raw water

Three batches of cubes were prepared for comparing compressive strength of different proportions and then by comparing compressive strength we prepared beam for flexural strength.

\subsection{Curing}

The specimens were removed from the mould after 24 hours of casting and they were placed in curing tank. Specimens were taken out from curing tank n 3, 7 and 28 days from the day when they were placed for curing. 


\section{International Journal of Innovations in Engineering and Science, www.ijies.net}

\section{VI- RESULTS \& DISCUSSION}

1) Average compressive strength of Raw Water Cubes

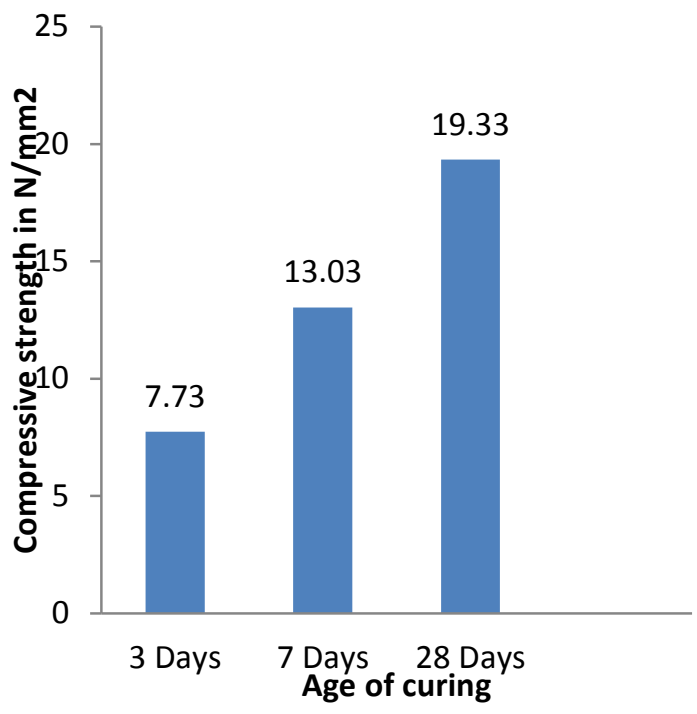

- 03 days compressive strength of raw water cubes is found as $7.73 \mathrm{~N} / \mathrm{mm} 2$.

- 07 days compressive strength of raw water cubes is found as $13.03 \mathrm{~N} / \mathrm{mm} 2$.

- 28 days compressive strength of raw water cubes is found as $19.33 \mathrm{~N} / \mathrm{mm} 2$.

2) Average compressive strength of Waste Wash Water Cubes

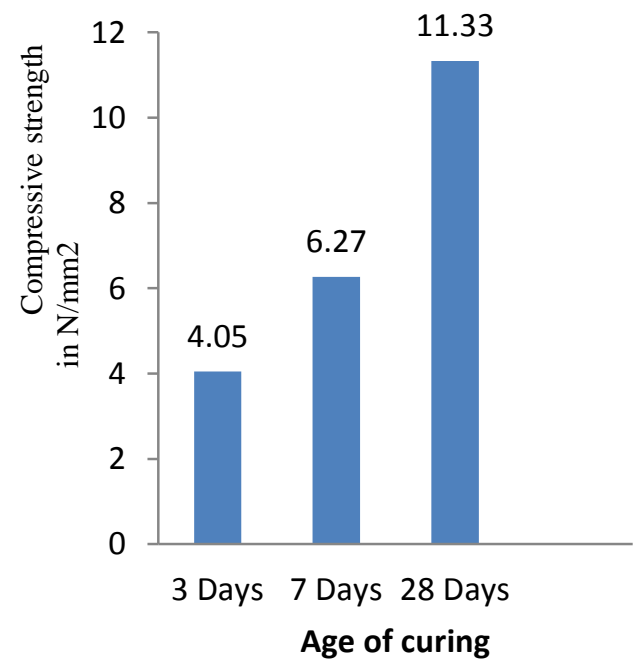

- 03 days compressive strength of waste wash water cubes is found as $4.05 \mathrm{~N} / \mathrm{mm} 2$.

- 07 days compressive strength of waste wash water cubes is found as $6.27 \mathrm{~N} / \mathrm{mm} 2$.
- 28 days compressive strength of waste wash water cubes is found as $11.33 \mathrm{~N} / \mathrm{mm} 2$.

3) Average compressive strength of 70:30 ( Treated : Raw water ) Cubes

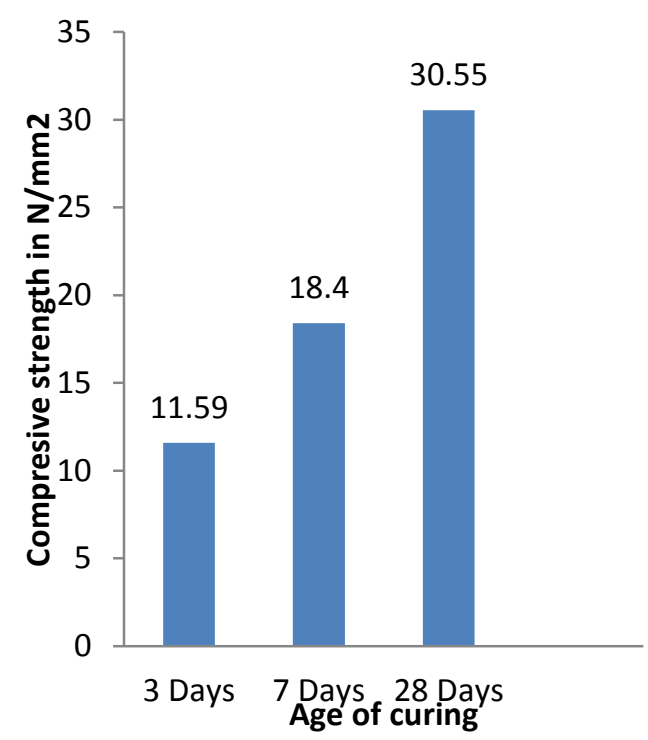

- 03 days compressive strength of cubes is found as $11.59 \mathrm{~N} / \mathrm{mm} 2$.

- 07 days compressive strength of cubes is found as $18.4 \mathrm{~N} / \mathrm{mm} 2$.

- 28 days compressive strength of cubes is found as $30.55 \mathrm{~N} / \mathrm{mm} 2$.

4) Flexural strength of 70:30 (Treated: Raw water) beam.

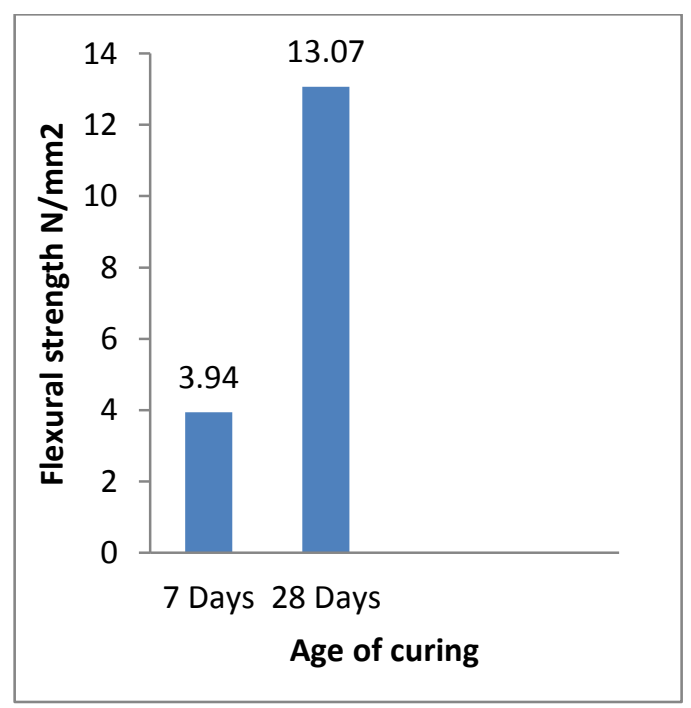

- 03 days Flexural strength of beams is found as 


\section{International Journal of Innovations in Engineering and Science, www.ijies.net}

\section{$3.94 \mathrm{~N} / \mathrm{mm} 2$}

- 28 days Flexural strength of beams is found as $13.07 \mathrm{~N} / \mathrm{mm} 2$.

\section{VII - CONCLUSIONS}

1. This study has shown that dumping of RMC wash water into ground promotes to land degradation. Rather than dumping it a attempt was made to treat the RMC wash water and make it reusable for concrete production. Ultimately after settling the waste water and separating oil and grease from the waste water and adjusting the ph of water it was used in concrete production. Compression strength results of cubes and flexural strength results of beams prepared using treated water were significant.

2. The results presented above clarifies that use of combination of treated water and raw water in ratio 70:30 shows higher compressive strength as compared to raw mixing water.

3. While using direct slurry water from RMC plant tends to reduce the compressive strength of concrete as compared to raw mixing water.

4. Also use of combination of treated water and raw water in ration 70:30 shows higher flexural strength as compared to raw mixing water.

5. Thus it can be concluded that wash waste water from RMC plant after proper treatment can be used as an alternate for raw mixing water in concrete production. This will directly impact the environment and achieve economy in the construction field.

\section{REFERENCE}

[1] Brazil, Luiz de Brito Prado Vieira, Antonio D. Figueiredo, Tacius Moriggi, Vanderley M John, "Waste Generation from the production of RMC", July 2019.

[2] Bhopal, (M.P.) India, Rahul Kumar, Dr. J.P. Tegar, "Critical Analysis of Properties of Ready Mix Concrete with Site Mix Concrete of Smart Road Project", Volume: 05 Issue: 06, 2395-0072, June2018.

[3] Pune (MH) India, Priyanka Jawale, Sanket Vaidya, Mohini Tandale, Mayur Patil, Sandhya Sabale, Shubham Mahamulkar, "Sustainable Use of Resources - Recycling of RMC used Wash Water in Mortar", Volume 6, Issue IV, 2321-9653, April 2018.

[4] Tamil Nadu, India, Krishnaraj, R. Suba Lakshmi and P.T. Ravichandran, "Utilisation of RMC waste with chemical admixtures to manufacturing of sustainable building components", Vol. 10, No. 2, 0974-1496, April - June 2017.

[5] Perlis, Malaysia, Aeslina Abdul Kadir, Shahiron Shahidan, Lau Hai Yee, Mohd Ikhmal Haqeem Hassan \& Mohd Mustafa Al Bakri Abdullah, "The effect on slurry water as a fresh water replacement in concrete properties", 2016.

[6] Turkey, Aynur Kazaz, Serdar Ulubeyli, Bayram Er, Volkan Arslan, Ahmet Arslan, Murat Atici, "Fresh RMC waste in construction project: A planning approach”, Nov 2015.

[7] Athens, Greece, Stamatis Tsimas and Monika Zervaki, "Reuse of By-Products from Ready-Mixed Concrete Plants for the Production of Cement Mortars", Volume 1, Issue 2, 152-162, 2013.

[8] South Africa, S. Ekolu and A. Dawneerangen, "Evaluation of recycled water recovered from a ready-mix concrete plant for reuse in concrete", vol. 52, no. 2, pp. 77-82, 2010.

[9] A. Sales, F. R. De-Souza and F. C. Almeida, "Mechanical properties of concrete produced with a composite of water treatment sludge and sawdust", vol. 25, no. 6, pp. 2793-2798, 2011.

[10] UK, B. J. Sealey, P. S. Phillips, G. J. Hill, "Waste management issues for the UK RMC industry ”, July 2001.

[11] Malaysia, G. L. Low, W. L. Ng, C. T. Tam and R. B. Heng, "Use of recycled cement- based slurry water for making concrete,", vol. 68, no. 4, pp. 47-55, 2007.

[12] F. Sandrolini and E. Franzoni, "Waste wash water recycling in ready-mixed concrete plants", vol. 31, no. 3, pp. 485-489, 2001.

[13] World Health Organization, (WHO), (2003). Guidelines for drinking water quality. Geneva

[14] Central Pollution Control Board - Guidelines for water quality management.

[15] 3025 Methods of sampling and test for water and waste water. 